\title{
Identification of a microscopically selected microorganism in milk samples ${ }^{1}$
}

\author{
Nathalie Bracke, ${ }^{*}$ Mario Van Poucke, $†$ Bram Baert, ${ }^{\star}$ Evelien Wynendaele, ${ }^{\star}$ Lobke De Bels,ł \\ Wim Van Den Broeck, $\neq$ Luc Peelman, $\dagger$ Christian Burvenich,§ and Bart De Spiegeleer* ${ }^{2}$ \\ *Drug Quality and Registration (DruQuaR) Group, Department of Pharmaceutical Analysis, Faculty of Pharmaceutical Sciences, Ghent University, \\ Harelbekestraat 72, 9000 Ghent, Belgium \\ †Department of Animal Nutrition, Genetics and Ethology, Faculty of Veterinary Medicine, Ghent University, Heidestraat 19, 9820 Merelbeke, \\ Belgium \\ ‡Department of Morphology, Faculty of Veterinary Medicine, Ghent University, Salisburylaan 133, 9820 Merelbeke, Belgium \\ $\S$ Department of Comparative Physiology and Biometrics, Faculty of Veterinary Medicine, Ghent University, Heidestraat 19, 9820 Merelbeke, \\ Belgium
}

\begin{abstract}
Identification of unwanted microbial contaminants microscopically observed in food products is challenging due to their low abundance in a complex matrix, quite often containing other microorganisms. Therefore, a selective identification method was developed using laser capture microdissection in combination with direct-captured cell PCR. This procedure was validated with Geobacillus stearothermophilus and further used to identify microbial contaminants present in some industrial milk samples. The microscopically observed contaminants were identified as mainly Methylobacterium species.
\end{abstract}

Key words: laser capture microdissection, cultivationindependent identification, bacterial contamination, direct-captured cell PCR

\section{INTRODUCTION}

The presence of bacterial contamination in food products represents a serious health threat to consumers worldwide (Tauxe et al., 2010). Microbial growth has a negative effect on product integrity and quality (i.e., the product fails to meet the customer expectations by the presence of unacceptably high numbers of microorganisms, spoilage, or contamination with pathogens and or microbial toxins). Microbial contamination can originate from the raw materials but also from microorganisms housed in a biofilm on the processing

\footnotetext{
Received April 17, 2013.

Accepted October 13, 2013

${ }^{1}$ Contributions: study design and directors: B. De Spiegeleer and L. Peelman; sample processing: N. Bracke and B. Baert; microtome: L. De Bels; laser capture microdissection: N. Bracke and B. Baert; DNA extraction: M. Van Poucke, N. Bracke, and B. Baert; amplification and sequencing: M. Van Poucke and N. Bracke; writing manuscript: N. Bracke; review of manuscript: B. De Spiegeleer, M. Van Poucke, E. Wynendaele, L. De Bels, L. Peelman, W. Van Den Broeck, and C. Burvenich.

${ }^{2}$ Corresponding author: Bart.DeSpiegeleer@UGent.be
}

equipment (Brooks and Flint, 2008; Van Houdt and Michiels, 2010). It is, therefore, of primary importance to identify and eliminate contaminants from a health and economical point of view.

Microscopy is still the gold standard for observing (and counting) bacteria in raw milk and other dairy products as a microbial quality control. It has proven to be a valuable, rapid, and reliable quality control routine tool used in the dairy industry. However, traditional identification methods for microbial contaminants rely on phenotypic identification using cultivation-based methods (European Directorate for the Quality of Medicines and HealthCare, 2013) and biochemical assays (Smith et al., 1972). These methods suffer from 3 major drawbacks. First, they can only be used for organisms that can be cultivated in vitro. This approach requires pure culture of the microorganism (i.e., a laboratory culture containing a single species derived from a mixed culture with many species), which takes, in the best case, $48 \mathrm{~h}$ due to the time necessary for dilutions, platings, and incubations. Second, heterogeneous samples make it difficult to give unambiguous results. And third, some strains exhibit unique biochemical characteristics that do not fit into patterns that have been used as a characteristic of any known genus and species. The most promising strategy for the classification leading to reliable identification would include as a first step the analysis of the $16 \mathrm{~S}$ rRNA gene (Olsen et al., 1986). However, preferential lysis of cells before a PCR-based approach will most likely bias the view of the composition of the microbial diversity in the sample (von Wintzingerode et al., 1997). Therefore, it is important to develop a method that can selectively isolate microorganisms for further identification in a cultivation-independent manner.

Single-cell gene/genome sequencing workflows are based on the physical isolation of individual cells and the use of these cells as templates for PCR. Single cells can be isolated via (1) micromanipulations (e.g., micropipette; Ishøy et al., 2006; Kvist et al., 2007), suffering 
from limited throughput as well as difficulties when working in complex growth or storage media (e.g., food matrices); (2) flow cytometry fluorescence-activated cell sorting (Müller and Nebe-von-Caron, 2010), where prior knowledge is necessary for staining (selective fluorophores); and (3) laser capture microdissection (LCM) for the microscopic selection of the microorganism of interest. Laser capture microdissection allows the selective isolation of cells under direct microscopic visualization by the transfer of laser energy to a thermolabile layer, which forms a polymer-cell composite (Emmert-Buck et al., 1996), followed by the removal of the cell from the heterogeneous sample. A few publications report the use of LCM for the identification of microorganisms in histological tissues, using fluorescently labeled oligonucleotide probes or primers (Ryan et al., 2004; Klitgaard et al., 2005; Wang et al., 2010; De Hertogh et al., 2012), as well as in complex environmental samples (Gloess et al., 2008; Yanagihara et al., 2011).

We developed an LCM-based approach for the identification of specific bacteria in dairy samples based on atypical morphology, starting from a limited number of cells. The bottlenecks that had to be overcome were the smaller cell sizes of microorganisms, lower amount of DNA, and the number of isolated cells necessary for further analysis with DNA, RNA, or proteins, which traditionally ranges between 100 and thousands of cells (Espina et al., 2006). Milk samples from a food industrial plant where an unidentified bacterium was present were then obtained and analyzed.

\section{MATERIALS AND METHODS}

\section{Specimens}

Geobacillus stearothermophilus was purchased from the Belgian Coordinated Collections of Microorganisms/ Laboratory for Microbiology of the Faculty of Sciences of Ghent University (BCCM/LMG) bacterial collection (LMG11163; Ghent University, Ghent, Belgium). The strain was grown at $55^{\circ} \mathrm{C}$ overnight in brain-heart infusion (BHI) medium and then harvested for further processing. The culture grown G. stearothermophilus was mixed with a milk sample (1:4 culture:milk) and embedded in agarose to make microscopic slides. The industrial milk sample was embedded in agarose as well, without prior manipulations.

\section{Sample Processing, Microtome, and Staining}

First, $500 \mu \mathrm{L}$ of sample was added to $500 \mu \mathrm{L}$ of $1 \%$ agarose and vortexed immediately for at least 10 s. The tube was placed at $4^{\circ} \mathrm{C}$ before the preparation of microscopic slices. The solidified agarose-embedded sample was transferred into an embedding holder. The holder was placed into an STP420 Tissue Processor (Thermo Scientific, Erembodegem, Belgium), which gradually dehydrated the sample (using an increasing alcohol series followed by isopropanol and xylene; all from Sigma-Aldrich, Diegem, Belgium) and embedded it in paraffin. Up to ten $8-\mu \mathrm{m}$-thick sections were prepared from each sample using presterilized microtome blades. The sections were then placed on gelatin-coated microscopic glass slides $(25 \times 75 \mathrm{~mm})$ and incubated on a hot plate $\left(60^{\circ} \mathrm{C}\right)$ for $1 \mathrm{~h}$ to allow the paraffin to melt onto the slide. For the staining procedure, the slides were dewaxed and hydrated in succeeding baths of xylene $(3 \times 5 \mathrm{~min})$, isopropanol $(1 \times 5 \mathrm{~min})$, and a decreasing alcohol series (10 s in 95, 80, 70, 50, and $0 \%$ alcohol, successively). Then, they were stained in $0.1 \%$ (mass/vol) aqueous methylene blue dye and dehydrated with an increasing alcohol series (10 s in 0, 50, 70, 80, and $95 \%$ alcohol $)$, isopropanol $(2 \times 5 \mathrm{~min})$, and xylene $(3 \times 5 \mathrm{~min})$ and finally air-dried, while microbial contamination was prevented.

\section{LCM}

Laser capture microdissection was performed using the Arcturus PixCell II laser capture microscope (Life Technologies, Gent, Belgium). All slides were viewed at a $400 \times$ magnification. Hand gloves were used throughout the whole LCM procedure to prevent contamination of the slides. The CapSure HS-LCM caps (Life Technologies) were pretreated with 30-min UV exposure at a maximum distance of $10 \mathrm{~cm}$ to neutralize potentially present DNA as polymerase template (Champlot et al., 2010). The cells of interest were isolated on the caps by applying a laser pulse. The magnitude of the laser pulse (i.e., spot size, intensity, and duration) was optimized to accurately remove the cells from the slide. For isolation of individual bacteria, the spot size was kept minimal (i.e., $7.5 \mu \mathrm{m})$, with an intensity of $60 \mathrm{~mW}( \pm 30)$ and a duration of $4 \mathrm{~ms}( \pm 1)$. After the desired cells were captured, a sterile $0.5-\mathrm{mL}$ tube was placed over the cap surface. The assembly was stored at room temperature.

\section{PCR: Amplification of the 16S rRNA Gene}

The thermolabile polymer on top of the cap, including the captured bacteria, was scratched off in a laminar flow hood with a sterile pipette tip and immediately submerged in the PCR mix. The primers used for amplification of the 16S RNA gene are listed in Table 1 (b16SF and 1495R). All primers were purchased from Life Technologies.

Prior to amplification, the PCR solutions and consumables were first decontaminated according to the 
Table 1. 16S ribosomal DNA primers for amplification and sequencing

\begin{tabular}{ll}
\hline Primer & Sequence $\left(5^{\prime} \rightarrow 3^{\prime}\right)$ \\
\hline $27 \mathrm{~F}$ & GAGAGTTTGATCCTGGCTCAG \\
b16SF & AGCAAACAGGATTAGATACCC \\
$1495 \mathrm{R}$ & CTACGGCTACCTTGTTACGA \\
Universal primer & CGACGTTGTAAAACGACGGCCAGT \\
\hline
\end{tabular}

procedure described in Champlot et al. (2010). Briefly, the DNA polymerase and primers were decontaminated by incubating the required quantity with heat-labile double-strand specific DNase (HL-dsDNase; ArcticZymes, Troms $\varnothing$, Norway), which leaves single-stranded primers intact while removing contaminating DNA. The PCR buffer and consumables were treated by UV irradiation (30 min at a maximum distance of $10 \mathrm{~cm}$ ).

The PCR reactions were performed in an Eppendorf Mastercycler (Eppendorf Nederland BV, Nijmegen, the Netherlands). The PCR mixture consisted of the thermolabile layer of the LCM cap (template), $2 \mathrm{mM}$ deoxyribonucleotide triphosphates (dNTP), 1× FastStart buffer (Roche, Brussels, Belgium), $25 \mu M$ primers, $0.5 \mathrm{U}$ of FastStart polymerase (Roche), and water (Mol Bio grade, 5 prime; VWR International BVBA, Leuven, Belgium) in a total volume of $10 \mu \mathrm{L}$. The PCR program consisted of 40 cycles $\left(30 \mathrm{~s}\right.$ at $95^{\circ} \mathrm{C}, 30 \mathrm{~s}$ at $62^{\circ} \mathrm{C}$, and $1.5 \mathrm{~min}$ at $72^{\circ} \mathrm{C}$ ). The denaturation temperature $\left(95^{\circ} \mathrm{C}\right)$ was maintained for 3.5 min before the first cycle and the extension temperature for an additional 4 min after the 40 cycles. Nontemplate controls were included in the PCR rounds [i.e., water, empty caps (not used for LCM), and caps with isolated background agarose shots]. As positive control, the DNA of G. stearothermophilus purified by the genomic DNA purification kit (Fermentas kit; Thermo Fisher) was included. To increase the 744-bp signal, the PCR reaction was repeated with $1 \mu \mathrm{L}$ of PCR product from the first PCR reaction as a template.

\section{Sequencing of the 165 Ribosomal DNA}

The PCR product was purified with a GeneClean II Kit (Anachem Ltd., Luton, UK), according to the kit instructions. The material was then used for cycle sequencing, using the ABI Prism BigDye V3.1 Terminator Cycle Sequencing kit (Applied Biosystems Inc., Foster City, CA). The $10-\mu \mathrm{L}$ reaction mixtures consisted of 0.5 $\mu \mathrm{L}$ of RR-mix, $5 \times$ sequencing buffer [in-house, made according to the kit instructions: $200 \mathrm{~m} M$ Tris- $\mathrm{HCl}(\mathrm{pH}$ 8) and $5 \mathrm{mM} \mathrm{MgCl} 2$; Sigma-Aldrich], $1 \times \mathrm{GC}$ (FastStart Polymerase kit; Roche), $300 \mathrm{n} M$ 1495R primer, and 300 ng of DNA. Reaction conditions were as follows: $2 \mathrm{~min}$ at $95^{\circ} \mathrm{C}$, followed by 30 cycles (denaturation at $95^{\circ} \mathrm{C}$ for $30 \mathrm{~s}$, extension for $15 \mathrm{~s}$ at $55^{\circ} \mathrm{C}$, and final extension for
4 min at $60^{\circ} \mathrm{C}$ ), and finally a hold at $4^{\circ} \mathrm{C}$ until further processing. Cycle sequence products were precipitated by adding $25 \mu \mathrm{L}$ of $95 \%$ ethanol and $1 \mu \mathrm{L}$ of $3 \mathrm{M}$ sodium acetate ( $\mathrm{pH} 4.6)$ to each cycle sequencing reaction $(10 \mu \mathrm{L})$. The samples were placed at room temperature for $15 \mathrm{~min}$ and centrifuged at $20,000 \times g$ for $15 \mathrm{~min}$ at room temperature. After precipitation, an additional wash of the pellet was performed with $125 \mu \mathrm{L}$ of $70 \%$ ethanol and centrifuged at 20,000 $\times \mathrm{g}$ for $5 \mathrm{~min}$ at room temperature. The pellet was dried in a SpeedVac concentrator, redissolved in formamide, and run on 50-cm capillaries of the ABI 3130XL genetic analyzer (Applied Biosystems Inc.) using POP-7 polymer. The obtained sequences were analyzed with DECIPHER software to check for possible chimeras (Wright et al., 2012).

\section{Clone Library of the Unknown Bacterium}

The 16S rRNA gene PCR products were purified using the GeneClean II kit, ligated into plasmid pCR2.1, and transformed into competent Escherichia coli cells using the TA cloning kit (Life Technologies), according to the manufacturer's protocol. Twelve clones were picked for plasmid isolation using an alkaline extraction procedure (Birnboim and Doly, 1979) and restriction analysis with EcoRI (New England Biolabs, Ipswich, MA). Clones of interest were processed for sequencing as described above, using the universal primer (Table $1)$.

\section{RESULTS AND DISCUSSION}

To allow identification of selected bacteria in a cultivation-independent manner, we developed an exceptional protocol. A few obstacles needed to be overcome. (1) Bacterial contaminants from food equipment-washing liquids come in low quantities and selective cultivation of these contaminants is not always straightforward. Therefore, it was necessary to downscale the number of cells needed for identification. (2) An adapted method for sample preparation, starting from complex liquid samples (e.g., bacterial culture, yogurt, milk, and industrial rinse samples from a food plant), had to be developed. Figure 1 gives an overview of the LCM procedure. In the first step, the sample is processed to obtain a solid matrix to perform sample sectioning by microtome (step 2), which results in paraffin-embedded samples fixed on a glass slide. In the third step, the bacterial cells are colored with an LCM-compatible dye, which is followed by capturing cells on top of an LCM cap (step 4). Finally, a 744-bp fragment of the 16S rRNA gene sequence is amplified via direct-captured cell PCR (dccPCR; step 5) and 


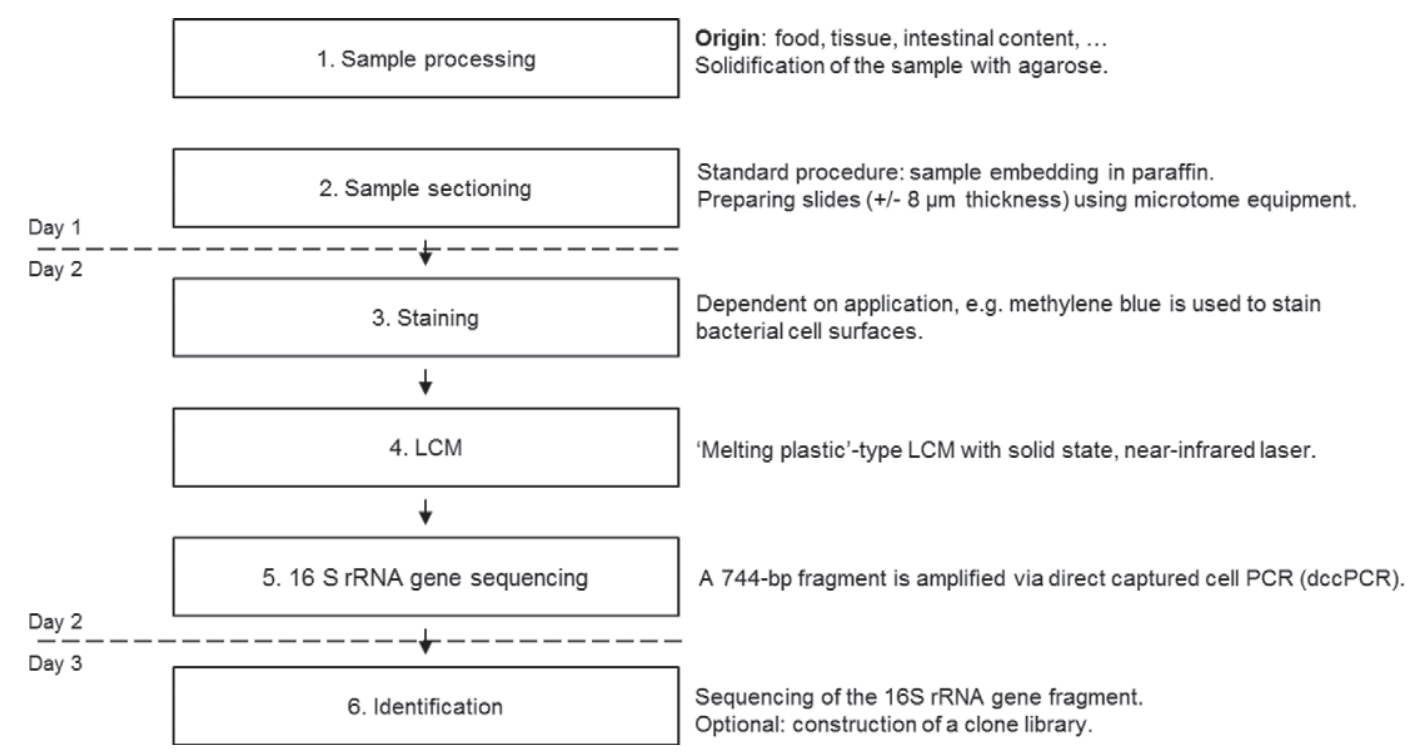

Figure 1. Cultivation-independent procedure to identify microorganisms using the laser capture microdissection (LCM) technology. A 3-dduration protocol was developed for routine use.

sequenced for bacterial identification (step 6). In the next sections, each step is separately discussed.

\section{Liquid Sample Processing}

Many food products as well as industrial rinsing samples are in a liquid state and need to be solidified to allow convenient LCM handling. The matrix (sample and solidifier) is composed of 2 phases: a liquid phase to allow uniform mixing and a solidifying phase, forming a block that can be processed the same way as tissue samples, while leaving the bacterial cells intact. Agarose is a well-known solidifier and was first used on a bacterial cell culture of G. stearothermophilus. Therefore, $500 \mu \mathrm{L}$ of a $1 \%$ agarose solution (temperature not more than $60^{\circ} \mathrm{C}$ ) was added to $500 \mu \mathrm{L}$ of a densely grown culture. The solidified matrix made embedding in paraffin and fine sectioning possible. Visualization of the bacterial cells was performed by the basic dye methylene blue, which binds to the negatively charged cell surfaces and is LCM compatible (Espina et al., 2006). Attention must be paid for the amount of organic material in the samples; this should be low to prevent high background signals, making it difficult to detect the bacterial contaminant via microscopy. After the staining procedure, the slides were completely airdried to prevent solvation of the thermolabile layer of the LCM cap.

\section{$L C M$}

The CapSure HS-LCM caps have $12-\mu \mathrm{m}$ ridges on the surface of the polymer, which prevent the polymer from touching the sample, except in the vicinity of the laser pulse. These features prevent contamination of other bacterial cells that are present in the sample or on top of the glass slide. The LCM caps contain a dye that helps to visualize the spots where the laser beam hit the cap. Furthermore, the dye prevents damage to the sample, caused by the laser energy. As the caps are not sterile, they were treated under UV light for $30 \mathrm{~min}$ to neutralize potentially present DNA as polymerase template.

\section{S rRNA Gene Amplification}

Because the protocol is based on PCR amplification of a limited amount of LCM-captured cells, the most challenging aspects were to prevent or treat non-sample bacterial DNA contamination and to generate sufficient DNA and sequencing data. The multi-strategy DNA decontamination procedure of the PCR components and consumables for hypersensitive PCR applications was compulsory and adequate for this purpose (Champlot et al., 2010).

We preferred dccPCR, by submerging the captured bacteria containing LCM cap polymer in the PCR mix, above PCR with bacterial DNA as template, isolated from the caps with the PicoPure DNA extraction kit (Life Technologies), because it involves fewer manipulations (quicker, cheaper, less chance of contamination, and less DNA degradation); it allows performing PCR with the whole cap content in a $10-\mu \mathrm{L}$ total volume and it results in a higher success rate. Experiments with 20 captured cells (or more) resulted in an almost 100\% success rate. Experiments with fewer cells are possible, 
but have a lower success rate and are more influenced by potential pre-PCR bacterial contamination. The use of 20 captured cells per cap was combined with a double PCR of 40 cycles, with the cap polymer as a template for the first PCR (dccPCR) and $1 \mu \mathrm{L}$ of amplicon from the first PCR as template for the second PCR to generate a sufficient amount of amplicon.

The protocol was optimized for a 744-bp fragment of the $16 \mathrm{~S}$ rRNA gene. The amplification of longer fragments was less successful due to DNA degradation during the pre-LCM steps. The sequence content of the 744-bp fragment should be discriminating enough for most applications (Wilck et al., 2001; Bosshard et al., 2003; Clarridge, 2004). However, if a higher level of identification is needed, the PCR could be extended to a multiplex. In case of a homogeneous bacterial population, direct sequencing should do the job. However, for a heterogeneous bacterial population, direct sequencing would lead to a complex chromatogram. In that case, the identification of the different bacteria would demand a cloning step of the amplicon of the second PCR and sequencing several individual clones.

\section{Identification of Microorganisms Using the LCM-Based Approach}

The LCM procedure was validated using G. stearothermophilus as model organism. Fifty cells were isolated and the polymer was removed from the LCM cap and subjected to PCR with the b16SF and 1495R primers. All included controls gave the expected results; therefore, our method was considered as reliable. The 744-bp product was purified and sequenced with the $1495 \mathrm{R}$ primer. A BLAST search (http://blast.ncbi.nlm.nih. gov/; Zhang et al., 2000) confirmed the identity of $G$. stearothermophilus (accession no. JQ743052.1).

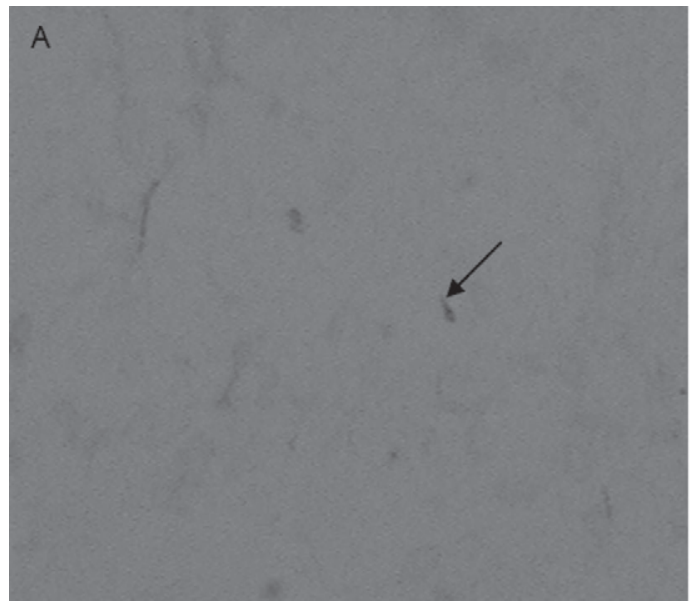

The same procedure was applied for the selective isolation (Figure 2) and identification of 20 cells of an unknown bacterium with atypical morphology. Our method indicated the presence of multiple species with a similar morphology instead of 1 species, as we observed a double peak pattern in the chromatogram after sequencing. Therefore, a cloning approach was performed to identify the microorganisms mainly as Methylobacterium species (99\% sequence identity with accession no. GU294332.1) and some others as chimeric clones.

The Methylobacterium genus includes a group of strictly aerobic, gram-negative, pink-pigmented, facultative methylotrophic bacteria characterized by their ability to utilize single-carbon compounds, such as methanol and formaldehyde via the serine pathway, as well as multi-carbon growth substrates. Members are ubiquitous in nature, detected in soil, freshwater, and lake sediments, as well as on other solid surfaces, including fermenters, and are known for their close association with plants (Nercessian et al., 2005; Crump and Koch, 2008; Kato et al., 2008; Podolich et al., 2009). Methylobacterium species were recovered in food-manufacturing plants in Japan (Kato et al., 2008) and in goat milk cheese (La Duc et al., 2007). Their resistance to high levels of chlorine has been described and it is possible that cleaning agents used in clean room environments may promote their growth (La Duc et al., 2007). In addition, methylobacteria have been reported to cause opportunistic infections in immunocompromised hosts (for example, central catheter infections; Brown et al., 1992; Sanders et al., 2000; Lee et al., 2004). The optimal temperature range for all Methylobacterium strains is in the range of 25 to $30^{\circ} \mathrm{C}$, although species have been recovered in more extreme conditions ranging from 60 to $90^{\circ} \mathrm{C}$ (Orphan et al., 2000), indicating the relative heat resistance.

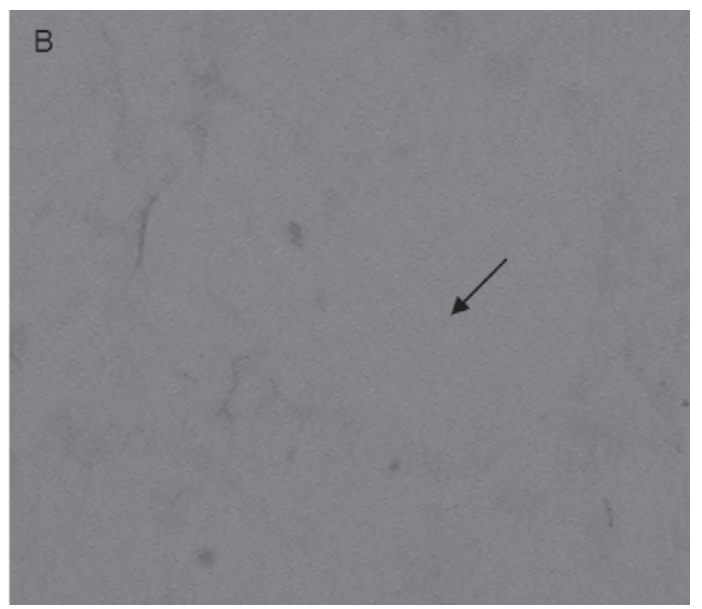

Figure 2. Accurate isolation of an unknown bacterium. (A) Microscopic slide before isolation of the unknown bacterium (indicated with an arrow). (B) The same microscopic slide after the isolation. 
The genus comprises 35 recognized species (Tani et al., 2012), some of which share higher than $97 \%$ (Stackebrandt and Goebel, 1994) and 98.6\% (Stackebrandt and Ebers, 2006) pairwise similarity of the $16 \mathrm{~S}$ rRNA gene sequences, rendering it difficult to differentiate between species. If species differentiation within the Methylobacterium genus is required, additional tests can be performed, such as growth on selective media, biochemical tests, determination of compounds they utilize as sole carbon and energy source, DNA-DNA hybridizations with Methylobacterium type strains, and $\mathrm{G}+\mathrm{C}$ content determination (Staley et al., 2005). Also, new approaches using whole-cell matrix-assisted laser desorption/ionization time-of-flight mass spectrometry (MALDI-TOF MS) analysis have been reported (Tani et al., 2012).

\section{CONCLUSIONS}

Identification of food and industrial plant contaminants constitute a key strategic challenge when only minute quantities of bacteria of interest are present in the sample. We have developed an identification procedure starting from complex liquid samples with a direct link to microscopy, using LCM. This procedure was successfully applied on industrial food plant samples for the identification of contaminants.

\section{REFERENCES}

Birnboim, H. C., and J. Doly. 1979. A rapid alkaline extraction procedure for screening recombinant plasmid DNA. Nucleic Acids Res. 7:1513-1523

Bosshard, P. P., S. Abels, R. Zbinden, E. C. Böttger, and M. Altwegg. 2003. Ribosomal DNA sequencing for identification of aerobic gram-positive rods in the clinical laboratory (an 18-month evaluation). J. Clin. Microbiol. 41:4134-4140.

Brooks, J. D., and S. H. Flint. 2008. Biofilms in the food industry: Problems and potential solutions. Int. J. Food Sci. Technol. 43:2163-2176.

Brown, W. J., R. L. Sautter, and A. E. Crist Jr. 1992. Susceptibility testing of clinical isolates of Methylobacterium species. Antimicrob. Agents Chemother. 36:1635-1638.

Champlot, S., C. Berthelot, M. Pruvost, E. A. Bennett, T. Grange, and E.-M. Geigl. 2010. An efficient multistrategy DNA decontamination procedure of $\mathrm{PCR}$ reagents for hypersensitive PCR applications. PLoS ONE 5:e13042.

Clarridge, J. E., III. 2004. Impact of $16 \mathrm{~S}$ rRNA gene sequence analysis for identification of bacteria on clinical microbiology and infectious diseases. Clin. Microbiol. Rev. 17:840-862.

Crump, B. C., and E. W. Koch. 2008. Attached bacterial populations shared by four species of aquatic angiosperms. Appl. Environ. Microbiol. 74:5948-5957.

De Hertogh, G., B. Lemmens, P. Verhasselt, R. de Hoogt, X. Sagaert, M. Joossens, G. Van Assche, P. Rutgeerts, S. Vermeire, and J. Aerssens. 2012. Assessment of the microbiota in microdissected tissues of Crohn's disease patients. Int. J. Inflam. 2012:505674.

Emmert-Buck, M. R., R. F. Bonner, P. D. Smith, R. F. Chuaqui, Z. Zhuang, S. R. Goldstein, R. A. Weiss, and L. A. Liotta. 1996. Laser capture microdissection. Science 274:998-1001.

Espina, V., J. D. Wulfkuhle, V. S. Calvert, A. VanMeter, W. Zhou, G. Coukos, D. H. Geho, E. F. Petricoin III, and L. A. Liotta. 2006. Laser-capture microdissection. Nat. Protoc. 1:586-603.
European Directorate for the Quality of Medicines and HealthCare. 2013. European Pharmacopoeia 7.8. Vol. 1. Council of Europe, Strasbourg, France.

Gloess, S., H.-P. Grossart, M. Allgaier, S. Ratering, and M. Hupfer 2008. Use of laser microdissection for phylogenetic characterization of polyphosphate-accumulating bacteria. Appl. Environ. Microbiol. 74:4231-4235.

Ishøy, T., T. Kvist, P. Westermann, and B. K. Ahring. 2006. An improved method for single cell isolation of prokaryotes from meso-, thermo- and hyperthermophilic environments using micromanipulation. Appl. Microbiol. Biotechnol. 69:510-514.

Kato, Y., M. Asahara, K. Goto, H. Kasai, and A. Yokota. 2008. Methylobacterium persicinum sp. nov., Methylobacterium komagatae sp. nov., Methylobacterium brachiatum sp. nov., Methylobacterium tardum sp. nov. and Methylobacterium gregans sp. nov., isolated from freshwater. Int. J. Syst. Evol. Microbiol. 58:1134-1141.

Klitgaard, K., L. Mølbak, T. K. Jensen, C. F. Lindboe, and M. Boye 2005. Laser capture microdissection of bacterial cells targeted by fluorescence in situ hybridization. Biotechniques 39:864-868.

Kvist, T., B. K. Ahring, R. S. Lasken, and P. Westermann. 2007. Specific single-cell isolation and genomic amplification of uncultured microorganisms. Appl. Microbiol. Biotechnol. 74:926-935.

La Duc, M. T., A. Dekas, S. Osman, C. Moissl, D. Newcombe, and K. Venkateswaran. 2007. Isolation and characterization of bacteria capable of tolerating the extreme conditions of clean room environments. Appl. Environ. Microbiol. 73:2600-2611.

Lee, C.-H., Y.-F. Tang, and J.-W. Liu. 2004. Underdiagnosis of urinary tract infection caused by Methylobacterium species with current standard processing of urine culture and its clinical implications. J. Med. Microbiol. 53:755-759.

Müller, S., and G. Nebe-von-Caron. 2010. Functional single-cell analyses: Flow cytometry and cell sorting of microbial populations and communities. FEMS Microbiol. Rev. 34:554-587.

Nercessian, O., E. Noyes, M. G. Kalyuzhnaya, M. E. Lidstrom, and L. Chistoserdova. 2005. Bacterial populations active in metabolism of $\mathrm{C}_{1}$ compounds in the sediment of Lake Washington, a freshwater lake. Appl. Environ. Microbiol. 71:6885-6899.

Olsen, G. J., D. J. Lane, S. J. Giovannoni, N. R. Pace, and D. A Stahl. 1986. Microbial ecology and evolution: A ribosomal RNA approach. Annu. Rev. Microbiol. 40:337-365.

Orphan, V. J., L. T. Taylor, D. Hafenbradl, and E. F. Delong. 2000. Culture-dependent and culture-independent characterization of microbial assemblages associated with high-temperature petroleum reservoirs. Appl. Environ. Microbiol. 66:700-711.

Podolich, O., V. Laschevskyy, L. Ovcharenko, N. Kozyrovska, and A. M. Pirttilä. 2009. Methylobacterium sp. resides in unculturable state in potato tissues in vitro and becomes culturable after induction by Pseudomonas fluorescens IMGB163. J. Appl. Microbiol. 106:728-737.

Ryan, P., R. G. Kelly, G. Lee, J. K. Collins, G. C. O'Sullivan, J. O'Connell, and F. Shanahan. 2004. Bacterial DNA within granulomas of patients with Crohn's disease - Detection by laser capture microdissection and PCR. Am. J. Gastroenterol. 99:1539-1543.

Sanders, J. W., J. W. Martin, M. Hooke, and J. Hooke. 2000. Methylobacterium mesophilicum infection: Case report and literature review of an unusual opportunistic pathogen. Clin. Infect. Dis. 30:936-938

Smith, P. B., K. M. Tomfohrde, D. L. Rhoden, and A. Balows. 1972. API system: A multitube micromethod for identification of Enterobacteriaceae. Appl. Microbiol. 24:449-452.

Stackebrandt, E., and J. Ebers. 2006. Taxonomic parameters revisited: Tarnished gold standards. Microbiol. Today 33:152-155.

Stackebrandt, E., and B. M. Goebel. 1994. Taxonomic note: A place for DNA-DNA reassociation and 16s rRNA sequence analysis in the present species definition in bacteriology. Int. J. Syst. Bacteriol. 44:846-849.

Staley, J. T., D. R. Boone, D. J. Brenner, P. De Vos, M. Goodfellow, N. R. Krieg, F. A. Rainey, G. M. Garrity, K. H. Schleifer, and G. Garrity. 2005. Bergey's Manual of Systematic Bacteriology, Vol. 2. 2nd ed. The Proteobacteria, Part C: The Alpha-, Beta-, Delta-, 
and Epsilonproteobacteria. Springer Science+Business Media Inc., New York, NY.

Tani, A., N. Sahin, Y. Matsuyama, T. Enomoto, N. Nishimura, A. Yokota, and K. Kimbara. 2012. High-throughput identification and screening of novel Methylobacterium species using whole-cell MALDI-TOF/MS analysis. PLoS ONE 7:e40784.

Tauxe, R. V., M. P. Doyle, T. Kuchenmüller, J. Schlundt, and C. E. Stein. 2010. Evolving public health approaches to the global challenge of foodborne infections. Int. J. Food Microbiol. 139(Suppl. 1):S16-S28.

Van Houdt, R., and C. Michiels. 2010. Biofilm formation and the food industry, a focus on the bacterial outer surface. J. Appl. Microbiol. 109:1117-1131.

von Wintzingerode, F., U. B. Göbel, and E. Stackebrandt. 1997. Determination of microbial diversity in environmental samples: Pitfalls of PCR-based rRNA analysis. FEMS Microbiol. Rev. 21:213-229.

Wang, Y., D. A. Antonopoulos, X. Zhu, L. Harrell, I. Hanan, J. C. Alverdy, F. Meyer, M. W. Musch, V. B. Young, and E. B. Chang.
2010. Laser capture microdissection and metagenomic analysis of intact mucosa-associated microbial communities of human colon. Appl. Microbiol. Biotechnol. 88:1333-1342.

Wilck, M. B., Y. Wu, J. G. Howe, J. Y. Crouch, and S. C. Edberg. 2001. Endocarditis caused by culture-negative organisms visible by Brown and Brenn staining: Utility of PCR and DNA sequencing for diagnosis. J. Clin. Microbiol. 39:2025-2027.

Wright, E. S., L. S. Yilmaz, and D. R. Noguera. 2012. DECIPHER, a search-based approach to chimera identification for $16 \mathrm{~S}$ rRNA sequences. Appl. Environ. Microbiol. 78:717-725.

Yanagihara, K., N. Niki, and T. Baba. 2011. Direct PCR amplification of the 16S rRNA gene from single microbial cells isolated from an Antarctic iceberg using laser microdissection microscopy. Polar Sci. 5:375-382.

Zhang, Z., S. Schwartz, L. Wagner, and W. Miller. 2000. A greedy algorithm for aligning DNA sequences. J. Comput. Biol. 7:203-214. 